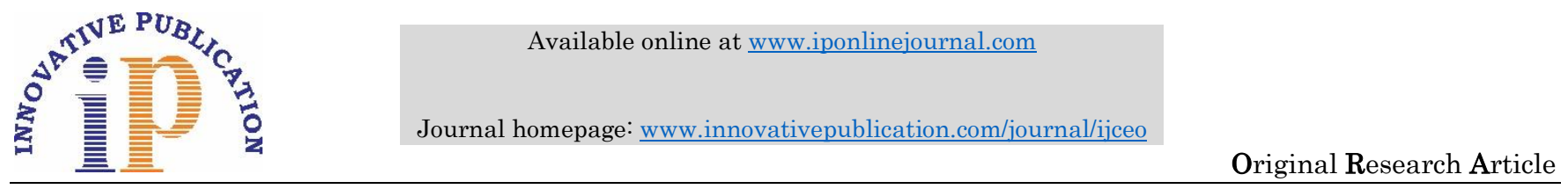

\title{
A comparative study of fasting serum lipid profile between glaucoma patients and controls
}

\author{
Munish Dhawan ${ }^{*}$, SP Singh², Swapnil Kamble ${ }^{3}$ \\ ${ }^{\mathbf{1}}$ Associate Professor, ${ }^{2}$ Professor, ${ }^{3}$ Junior Resident, Dept. of Ophthalmology, Guru Gobind Singh Medical College and Hospital, Faridkot, \\ Punjab, India
}

\section{Article Info}

Received: $16^{\text {th }}$ February, 2019

Accepted: $26^{\text {th }}$ March, 2019

Published Online: $9^{\text {th }}$ September, 2019

Keywords: Age, Glaucoma, Lipid profile, Open angle, Total cholesterol.

\begin{abstract}
Glaucoma constitutes $10 \%$ of blindness worldwide which is the third most common cause of blindness with majority of people being undiagnosed in developing countries.

Aims: To assess and compare serum lipid profile between normotensive, non diabetic POAG patients and normotensive, non diabetic non glaucoma controls.

Results: 1: Mean total cholesterol levels were $(219 \pm 60.010) \mathrm{mg} / \mathrm{dl}$ and $(191.26 \pm 43.167)$ $\mathrm{mg} / \mathrm{dl}$ in glaucoma patients and controls respectively and the difference was statistically significant $(\mathrm{p}<0.011) ; 2$ : Statistically significant difference $(\mathrm{p}<0.019)$ was observed in mean LDL-C value in glaucoma patients $(152.26 \pm 58.791) \mathrm{mg} / \mathrm{dl}$ and controls

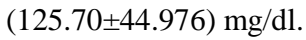

Conclusion: Higher total cholesterol levels and LDL-C levels were found in glaucoma patients as compared to controls. While there was no significant difference of serum triglycerides, HDL-C, VLDL-C levels between both the groups.
\end{abstract}

\section{Introduction}

Word glaucoma derives from Greek word 'glaucos' which means watery or diluted blue and referred to bluish discoloration of pupil as described by Hippocrates. The condition was later called as 'ypochyma' and corresponds to cataract. Later on with actual understanding of glaucoma with advanced examination and investigation techniques, the true definition was devised. ${ }^{2}$

Glaucoma is a chronic, progressive optic neuropathy leading to damage of optic nerve by a group of ocular conditions causing loss of visual function. Raised intraocular pressure is the most common modifiable risk factor. ${ }^{3}$

It is a leading cause of irreversible blindness throughout the world. World Health Organization statistics, published in 1995, indicate that glaucoma accounts for blindness in 5.1 million persons $(13.5 \%)$ of global blindness \{behind cataract 15.8 million (41.8\%) and trachoma 5.9 million (15.5\%) persons of global blindness). ${ }^{4}$

The disease, particularly during the initial stages, is asymptomatic and it has been said that half of the people who suffer from the disease are unaware of its occurrence. However, gradually they develop signs such as increasing IOP, cupping of the optic disk, and distortion of visual field. Though rise in intraocular pressure is an important risk factor for open-angle glaucoma, but it is not diagnostic of the disease. Visual field testing (perimetry) plays an important role in diagnosis and management of glaucoma.

Various etiological factors have been proposed but metabolic disorders such as diabetes mellitus, hypercholesterolemia, hypertriglyceridemia, may have an important role in the appearance of this disease. ${ }^{5}$

It is confirmed that atherosclerosis with higher intraocular pressure has a bad influence on pulse volume level in glaucoma. ${ }^{6}$

So, we have done this study to evaluate the fasting lipid profile level in normotensive and non-diabetic glaucoma patients coming to our hospital in OPD of Ophthalmology department G.G.S. Medical College, Faridkot.

\section{Materials and Methods}

The study was conducted on 50 non diabetic normotensive cases diagnosed as POAG and 50 controls i.e. normal healthy volunteers visiting the OPD. The sample size was taken as per the feasibility to fulfil the inclusion criteria among the patients visiting the OPD of department of Ophthalmology, Guru Gobind Singh Medical College and Hospital, Faridkot.

\section{Inclusion Criteria}

Case: A total of 50 cases with established POAG, both male and female, and aged between 30-70 years were included.

The cases were primarily selected on the basis of detailed history, clinical features, intraocular pressure, gonioscopic findings and visual field analysis.

Control: 50 non hypertensive, non diabetic individuals were included in control group with age 30-70 years.

\section{Exclusion Criteria}

1. Patients with diabetes mellitus.

\footnotetext{
*Corresponding Author: Munish Dhawan, Professor and HOD, Dept. of Ophthalmology, Guru Gobind Singh Medical College and Hospital, Faridkot, Punjab, India

Email: drmunishdhawan@gmail.com

http://doi.org/10.18231/j.ijceo.2019.087
} 
2. All hypertensive patients with blood pressure more than 120/80 mm Hg (according to JNC 7 classification). ${ }^{7}$

3. Patient with all other glaucoma except POAG (angle closure glaucoma, post uveitic glaucoma etc.)

4. Patients on lipid lowering drugs and IOP lowering medication (e.g. topical beta blockers, diuretics, statins)

5. Other systemic diseases altering the serum lipid levels (e.g. hypothyroidism, nephrotic syndrome)

\section{Cases were diagnosed as POAG on the basis of following ophthalmic examinations}

1. Visual acuity:

Both corrected and uncorrected visual acuity was measured for distant (Snellen's visual acuity chart) and near vision.

2. Slit lamp examination to examine :

a. Conjunctival congestion

b. Corneal edema and haze

c. Depth of anterior chamber, aqueous cells and flare

d. Iris for atrophy, rubiosis, synechiae, iridodonesis

e. Pupillary reaction and size

f. Anterior and posterior surface of lens and lenticular atrophy

3. Intraocular pressure (IOP) was measured at the same slit lamp using goldmann applanation tonometry by the single observer. The applanation tonometry measurements are affected by central corneal thickness (CCT). CCT was measured by ultrasonic pachymetry. For every 10 micron difference in CCT from 520 micron, $0.7 \mathrm{mmHg}$ was used as correction factor. ${ }^{8}$

4. Pachymetry using ultrasonic pachymeter to measure central corneal thickness (CCT).

5. Gonioscopy was done by using Goldman three mirror lens to visualise the angle of anterior chamber.

\section{Angle grading was done according to Shaffer grading system. ${ }^{9}$ : \\ Grade 0 - Closed angle}

Grade $1\left(10^{\circ}\right)$ - only Schwalbe's line can be identified

Grade $2\left(20^{\circ}\right)$ - Schwalbe's line and trabecular meshwork can be identified

Grade $3\left(25^{\circ}-35^{\circ}\right)$ - upto scleral spur can be identified

Grade $4\left(35^{\circ}-45^{\circ}\right)$ - Schwalbe's line, trabecular meshwork, scleral spur and ciliary body can be visualized

6. Perimetry: All the patients underwent visual field assessment with Automated Humphrey Visual Field Analyser using the central 30-2 SITA (Swedish
Interactive Threshold Algorithm) standard on day of admission.

7. Fundus examination was done by direct and indirect ophthalmoscopy to diagnose the glaucomatous optic disc cupping

\section{Following investigations were done in cases and controls}

1. Fasting serum lipid levels. ${ }^{10-13}$

2. Blood pressure

3. Fasting blood sugar

4. HbA1c level

\section{Results}

Obtained data was statistically analysed using MannWhitney T test.

Mean total cholesterol levels were $(219 \pm 60.010) \mathrm{mg} / \mathrm{dl}$ and $(191.26 \pm 43.167) \mathrm{mg} / \mathrm{dl}$ in glaucoma patients and controls respectively and the difference was statistically significant $(\mathrm{p}<0.011)$. Statistically significant difference $(\mathrm{p}$ $<0.019$ ) was observed in mean LDL-C value in glaucoma patients $(152.26 \pm 58.791) \mathrm{mg} / \mathrm{dl}$ and controls $(125.70 \pm 44.976) \mathrm{mg} / \mathrm{dl}$. Whereas regarding mean triglycerides values there was no statistically significant difference $(\mathrm{p}<0.227)$ between glaucoma patients $(137.18 \pm 16.101) \mathrm{mg} / \mathrm{dl}$ and controls $(131.18 \pm 22.168) \mathrm{mg} / \mathrm{dl}$. Glaucoma patients and controls had mean HDL-C value of $(39.90 \pm 9.410) \mathrm{mg} / \mathrm{dl}$ and $(39.72 \pm 9.368) \mathrm{mg} / \mathrm{dl}$ respectively with no significant difference $(\mathrm{p}<0.942)$. In glaucoma patients and controls mean VLDL-C values were $(32.84 \pm 38.969) \mathrm{mg} / \mathrm{dl}$ and $(26.24 \pm 4.364) \mathrm{mg} / \mathrm{dl}$ respectively with statistically no significant difference $(\mathrm{p}<0.203)$.

\section{Discussion}

In this present study patients with primary open angle glaucoma there is rise in serum total cholesterol levels and LDL-C levels as compared to controls which is statistically significant. While serum triglycerides, HDL-C, VLDL-C levels are not significant statistically as compared to controls.

In an another study in 2016, the study conducted on 50 cases and 50 controls to assess and compare serum lipid profile between normotensive, non-diabetic glaucoma patients and controls. Results of the study showed that there was significant increase in total cholesterol and LDL-C in glaucoma patients compared to controls. However, no significant difference in TGL-C, VLDL-C and HDL-C was seen between the two groups. ${ }^{14}$

Table 1: Fasting lipidprofile in glaucoma patients and controls

\begin{tabular}{|c|c|c|c|c|c|}
\hline \multicolumn{7}{|c|}{ Controls (mg/dl) } & Glaucoma Patients (mg/dl) & \multirow{2}{*}{ P-Value } \\
& Mean & SD & Mean & SD & \\
\hline & 191.26 & 43.167 & 219.58 & 60.010 & 0.011 \\
\hline Total cholesterol & 131.18 & 22.168 & 137.18 & 16.101 & 0.227 \\
\hline Triglycerides & 39.72 & 9.368 & 39.90 & 9.410 & 0.942 \\
\hline HDL-C & 125.70 & 44.976 & 152.26 & 58.791 & 0.019 \\
\hline LDL-C & 26.24 & 4.364 & 32.84 & 38.969 & 0.203 \\
\hline VLDL-C & \multicolumn{5}{|l}{} \\
\hline SD: Standard Daviation
\end{tabular}


In 2014, a study was done on 40 primary Open-angle glaucoma (POAG) patients (cases) and 40 healthy individuals (controls). In order to diagnose POAG, intra ocular pressure (IOP) was measured by means of Applanation tonometry, and then was confirmed through perimetry and ophthalmoscope. After a fasting of 12 hours, blood samples were derived to determine serum level of triglyceride and cholesterol levels. Then, the results of the tests together with the participants' demographic information were individually registered in a questionnaire. There was a positive association between POAG and dyslipidemia for hypercholesterolemia and for hypertriglyceridemia and concluded hyperlipidemia can be a risk factor of getting POAG. ${ }^{15}$

\section{Conclusion}

Our study was a case control study conducted in the department of Ophthalmology, G.G.S Medical College and Hospital, Faridkot. It included 100 patients visiting Ophthalmology OPD out of which 50 were cases and 50 were controls.

We found the comparison of fasting serum lipid levels between the cases and controls and their association with primary open angle glaucoma. We obtained following results:

1. Mean total cholesterol levels were significantly different in both the groups with higher levels in glaucoma patients. Hence there was positive association between total cholesterol levels and primary open angle glaucoma in our study.

2. We found the association of LDL levels with the primary open angle glaucoma because in our study the mean serum LDL levels were significantly higher in the cases than the controls.

3. No significant difference was found in mean serum triglyceride, HDL-C, VLDL-C levels between both groups.

\section{Source of Funding: None.}

\section{Conflict of Interest: None.}

\section{References}

1. Stein JD, Newman-Casey PA, Talwar N, Nan B, Richards JE, Musch DC. The relationship between statin use and open-angle glaucoma. Ophthalmol. 2012;119(10):2074-81.
2. Adeola OlukoredeOnokaya Quality Of Life of Primary Open Angle Glaucoma Patients in Lagos, Nigeria: Clinical And Sociodemographic Correlates. J Glaucoma. 2012;21:287-95.

3. Ramanjit S, Radhika T. Parsons' Diseases of the Eye.19th Edition. India: Elsevier; 2003:299-10.

4. Thylefors B, Negrel AD, Pararajasegaram R, Dadzie KY. Global data on blindness. Bulletin of the World Health Organization. 1995;73(1):115.

5. Pavljašević S, Ašćerić M. Primary open-angle glaucoma and serum lipids. Bosnian journal of basic medical sciences. 2009 Feb;9(1):85.

6. Alajbegović R. Primarniglaukom. Sarajevo-Publishing, Sarajevo 1997, pp. 32-33.

7. Chobanian AV, Bakris GL, Black HR, Cushman WC, Green LA, Izzo Jr JL, et al. The seventh report of the joint national committee on prevention, detection, evaluation, and treatment of high blood pressure: the JNC 7 report. JAMA. 2003;289(19):2560-71.

8. Philip Severn, Scott Fraser, Tracy Finch and Carl May. 'Which quality of life score is best for glaucoma patients and why'. BMC Ophthalmol 2008;8:2.

9. Kolker AE, Hetherington J Jr, eds. Becker and Shaffer's diagnosis and therapy of the glaucomas, 5 th edition St. Louis: CV Mosby; 1976.

10. Triglycerides Kit (GPO / PAP Method). For the determination of Triglycerides in Serum or Plasma (For in vitro diagnostic use only).

11. Cholesterol Kit (CHOD-PAP Method) For the Determination of Cholesterol in Serum or Plasma (For invitro diagnostic use only).

12. Lopes-Virella MF, Stone P, Ellis S, Colwell JA. Cholesterol determination in high-density lipoproteins separated by three different methods. Clin Chem. 1977;23(5):882-4.

13. Fukuyama N, Homma K, Wakana N, Kudo K, Suyama A, Ohazama $\mathrm{H}$, et al. Validation of the Friedewald equation for evaluation of plasma LDL-cholesterol. J Clin Biochem Nutr. 2007;43(1):1-5.

14. Saikia M, Phukan JK, Gogoi B, Goswami RK. A Study of Serum Fasting Lipid Profile and Serum Total Protein and Fractions in Normotensive Non-Diabetic Glaucoma Patients. Global J Res Anal. 2016;5(6).

15. Davari MH, Kazemi T, Rezai A. A Survey of the Relationship between Serum Cholesterol and Triglyceride to Glaucoma: A Case Control Study. J Basic Appl Sci. 2014;10:39.

How to cite this article: Dhawan M, Singh SP, Kamble S. A comparative study of fasting serum lipid profile between glaucoma patients and controls. Indian J Clin Exp Ophthalmol 2019;5(3):367-369. 